\title{
ON NATIONS AND INTERNATIONAL BOUNDARIES - THE CASE OF THE MEDITERRANEAN REGION
}

\author{
Gideon Biger \\ Department of Geography and Human Environment, Tel Aviv University \\ Tel-Aviv University, Ramat-Aviv, Zelig 10 st. Afeka, Tel-Aviv 6997801: Israel \\ bigergideon@gmail.com
}

\begin{abstract}
The world seems mainly to comprise nation states that are independent and based on one nation, if sometimes with certain minorities within it. Thus, at first glance the model seems to be of 'a nation establishing its boundaries'. However, a 'boundaries that made a nation' model also in fact exists - in which nations were created after boundaries were laid down. The independent states in the Mediterranean region forming the main subject of study here are found to belong to both of the above models, with the result that they place overall between the European model of 'nation states' and the African and Middle Eastern model by which 'boundaries make nations'.
\end{abstract}

Keywords: boundaries, historical model, independent states, Mediterranean region, nations.

Today's political world map features some 200 independent states separated from each other by various kinds of boundary (and mostly by designated borders). The present article resembles research published a decade ago (Biger, 2011) that tried to depict the relationship between nations and international boundaries in Europe. Here the emphasis is on the same phenomenon as manifested in the Mediterranean region, denoting countries with a coast on that Sea, though also acknowledging the way in which certain countries like Portugal, or some in the Balkans, may also be perceived as belonging to that 'Mediterranean region'. So together, that today denotes some 21 independent states (King, Proudfoot \& Smith, 1997) - in an area whose political map developed through a long historical process that may in some sense be never-ending. Nevertheless, each independent country has a special story to tell on how it came into existence.

On the basis of published scientific research and general observation of the countries in question, reference to the same basic historical=geography model addressing the relationship between nations and international boundaries can be used to present countries' current statuses. In the context of this paper, 'current' actually refers to the situation pertaining in 2020. Only rarely is the past situation invoked - where this helps to portray the uniqueness of given countries. 


\section{Nation-states and non-nation-states as seen from a global perspective}

Today's world divides up into more than 200 different independent countries, and the numbers seemingly go on growing (WF, 2018). The countries in question are delineated by more than 300 territorial boundaries - borders - between them, serving to define and delimit their territory (Biger, 1995). It as in line with national criteria that many of the states in question came into existence (and most especially those that are newly-independent, having only been founded in the last few decades). So it was that a united, multi-national Yugoslavia gave way to independent nation-states that are six or seven in number (the independent status of Kosovo is still under debate). In a similar way, no fewer than 16 new nation-states emerged out of the former Soviet Union. The establishment - by separation - of the Czechia and Slovakia was also based on national criteria, as has been the case of East Timor. Moreover, the revival of ethnic nationalism (with many peoples claiming and fighting for political freedom and territorial integrity by reference to ethnic identity and solidarity), can lead to the establishment of more independent states in the future.

Standing in contrast to the above are the many independent states (like Canada, South Africa or even Belgium) that were established in the late 19th century or early 20th century, and are not based on either national or ethnic criteria. Beyond that, the establishment of the European Union as a multinational entity, as well as worldwide discussion of a 'borderless world', might point to another, different, direction, in which national identity would not be the leading attribute of states or other state-like polities.

\section{Nations and peoples}

There is no single definition of what constitutes a people, nation, or ethnic group. The Oxford American dictionary describes a nation as 'a large community of people of mainly common descent, language, history, etc., usually inhabiting a particular territory and under one government' (Ehrlich, Flexner, Carruth \& Hawkins, 1980). Thus 'people' are the persons composing a community or tribe or race or nation. Lanyi and McWilliams (1966) said that 'a nation implies a common culture, common symbols, and a particular view of the world which is distinct from other world views. What makes a nation different from other cultural groups, however, is that one of the symbols associated with the values and attitudes is a particular piece of territory'.

The Encyclopaedia of the Peoples of the World (Gonen, 1993) in turn uses certain criteria in its definition of a people, either alone or in combination. It resorts to common history; distinct language, shared traditions, religion, or folklore; a common identity maintained in the face of strong pressures to assimilate; self-designation; and territorial concentration. Clearly all of these factors can be used in defining a nation; and in line with such criteria the Encyclopaedia in question offers some 2000 entries dealing with different peoples, nations and ethnic groups that continue to exist in our world. When this is set against the aforementioned total of less than 150 nation-states, a question arises as to who else might be 'entitled' to have an independent state of their own. However, this is not in fact a question for the present article.

The basic requirements of an independent state have been defined as: a territory of its own, defined by recognised boundaries, population and governability, but also in receipt of international recognition vis-à-vis status as a sovereign state (Muir, 1975, p. 28). In line with that, this 
presentation seeks: 1 ) to address two of the components referred to, i.e. territorial boundaries and population, by dealing with the overall pattern of the nation-state versus the non-nation-state as seen from a global perspective, and especially in terms of relations between nations, boundaries and states; and 2) to take a close look at a specific case from Europe.

\section{Nation-states versus multinational states}

Most of the independent states in the world today are in some way founded upon their national character. Back in 1975, R. Muir (1975, p. 88-89) presented, after Minogue (1967, p. 13-17.), a three-category classification of forms of nationalism associated with nation-states in existence (a further 3 categories relate to entities not within states). The classification relates to:

1. ante-state nationalism (i.e. developed prior to the nation-state's coming into existence).

2. post-state nationalism (developed via integration of diverse cultures cocooned within an existing state).

3. Third-World nationalism, characterising peoples who come together to resist colonialism.

As the world now knows more than one new state emerging in the absence of any resistance to a colonial power, the second and the third categories may be merged, leaving two main global models for the relationship between nations and states. One of these would be the European-Asian ('Old-World') model, while the other is an American-African-Oceania (in some sense 'New-World') model. In turn, as one of the main characteristics of the modern state relates to the presence of an international boundary marking territorial sovereignty (Muir, 1975), it is possible for the nation-state model to be presented as a nation-boundaries model.

\section{The nation-boundaries model}

Two simple situations can be invoked as the relationship between nations and boundaries is described. Model 1 presents the classical nation-state, i.e. a situation in which a nation may exist long before its state's international boundary is demarcated, with the boundary then being placed to include as many people of the given nation as possible within the boundaries of the state that has become independent.

Model 2 in turn presents a situation whereby the demarcation of boundary lines is actually the basic force involved in creating the nation. In this situation a new state takes shape within boundaries that have little or nothing to do with the dispersion of tribes, peoples or nations. What then happens is that the inhabitants of the particular political area become a nation (which never existed before), by way of a prolonged process of development.

\section{The nation-before-boundary ('Old-World') model}

The 'nation before boundaries' situation for example presents Italy as the country of an Italian nation; as well as Sweden and Thailand as countries of the Swedish and Thai nations. Seen from a global perspective, this model applies mainly to the European and the Asian continents, i.e. the 'Old World'. Europe is basically a continent of nation-states, as we see with Scandinavia, Poland, the Baltic countries, Hungary, Bulgaria and others. Asia's independent states mostly also fit 
this pattern. Thus Japan is the country of the Japanese nation, and China the country of the Chinese nation (ostensibly at least, as there are of course minorities; and there are also the Laotian and Cambodian nations, and things like the Uzbek and Kazakh nations - all of which existed de facto long before the modern boundaries of their independent states of Laos, Cambodia, Uzbekistan and Kazakhstan were laid down. The same holds true for Mongolia, Afghanistan, Kyrgyzstan, and other eastern and central Asian states. The Vietnamese and Korean nations both found themselves cut in two, though Vietnam is now unified, even as two Korean states remain. Even India and Pakistan, though by no means homogeneous ethnically, were formed basically in line with the distribution of the Hindus and Moslems living in the Indian sub-continent.

All of these independent states in fact include certain national minorities that do not see themselves as connected to the dominant nation within the political boundaries; but they are still based around a majority of one ethnic nation. Although most of today's boundaries of the Asian states are borders delineated by European colonial powers, the drawing of those lines nevertheless accorded with the dispersion of the dominate nation-inhabitants in a given area. Nevertheless, there are certain exceptions in Asia (mainly the Middle East), and that situation will gain discussion later (Prescott, 1975).

\section{The boundaries-before-nation ('New-World') model}

The 'boundaries before nation' situation can characterise the Americas, Africa and Oceania as continents, and thus what are in some sense 'New-World' countries. Thus, the Argentine and Canadian nations, as well as the Nigerian and Kenyan nations or the Australian nation were all created through a mingling of those living in the area demarcated by a line, as these never existed as special nations before. Although there are some exceptions (in Africa), it would basically seem that the independent countries of the American continent from Canada to Chile (all of which now seek to assert and present their nationhood) exist where there was no nation before independence (Girot, 1994). The pre-Colombian map of America has nothing to do with the modern political map of the American continent of today. There never was a Colombian or Guatemalan nation before the respective countries' independence (Ireland, 1971), and even the American Nation as it is now was created by people which lived and still live between two boundary lines, a northern one with Canada and a southern one separating the United States from Mexico. There were also some local tribes and nations that joined new immigrants from all over the world in mingling and creating the new American nation.

The process was rather different in Africa. With certain exceptions (like those of Ethiopia, Lesotho and Botswana, and to some extent also Morocco and Egypt), most of the 'new' African states emerged as shaped by old colonial administrative lines, which took little or no notice of the existence and ranges of nations and tribes. The modern political map of Africa is thus an outcome of the colonial division from the late 19th century, combined with local imperial divisions of the mainly British and French colonies that made up Africa (Brownlie, 1979). This means that nearly all independent African states have a multi-national or multi-people society now working to form a united nation within the boundaries. From South Africa in the south, through Namibia, Zimbabwe, Tanzania, Kenya and Uganda to Congo, Chad, Mauritania, Ghana, and others (Touval, 1972) the same pattern is matched by these countries and by all others. The same holds true for Oceania, where most independent countries are remains of past colonial empires that in essence created the different countries we find today in this part of the globe. 


\section{The Mediterranean case}

A unique feature of the Mediterranean region (also as the cradle of civilisation in general) is that it may serve to epitomise both of the aforementioned models. Of the 21 independent states in the Mediterranean: Spain, France, Monaco, Italy, Slovenia, Croatia, Bosnia, Montenegro, Albania, Greece, Turkey, Cyprus, Syria, Lebanon, Israel, Egypt, Libya, Tunisia, Algeria, Morocco and Malta (to which one might add the unrecognised independent Palestinian Authority (in its Gaza Strip part), as well as Northern Cyprus and the British Overseas Territory of Gibraltar), about half can represent countries built around a dominant nation. Examples here include France (notwithstanding a history that brought together French, Alsatian, Provencal, Basque and other people), as well as Italy, Slovenia, Croatia, Montenegro, Albania, Greece, Turkey, Malta, Israel and Cyprus, and partly also Egypt and Morocco). The remaining polities would then represent 'nation made by boundaries' states, in the sense that they are not founded and built around a dominant nation (Fig. 1).

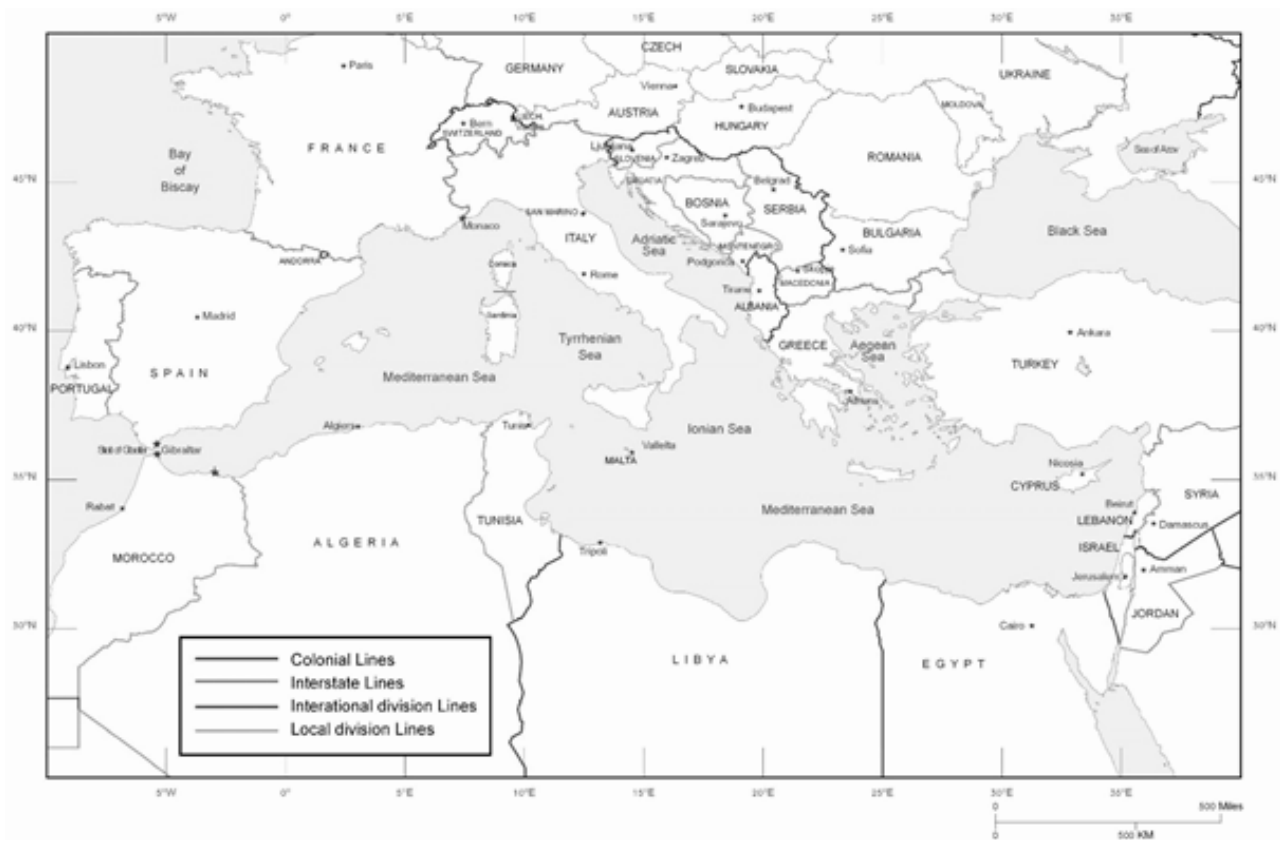

Figure 1. The basis upon which boundaries in the Mediterranean region were created (Kosovo is missing from here, as is Northern Cyprus)

Source: map by the author.

The group of 'nation-states' here is well-known, so that leaves the countries that are different, which may also be grouped by reference to the three different continents brought together by the Mediterranean Sea. 


\section{Europe}

Mediterranean Europe has two states in the 'nations made by boundaries' category, i.e. Monaco and Spain. Monaco has been independent since the $17^{\text {th }}$ century, allowing the 30,000 local Monegasques of Monaco - not actually different from the people in the surrounding area (Gonen, 1993, p. 408-409) - to form a nation comprising those who reside beyond a border with France - as actually one of the oldest political boundaries of this kind anywhere in the world.

The case of Spain is in turn a special one, on the basis of a state formed in 1492 and sealed into existence by the marriage of Isabella of Castile and Ferdinand of Aragon. However, this state operates within boundaries with Portugal established respectively in 1297 and 1479 (with Castile), as well as a border with France (from 1659). This leaves the united territory of Spain as more than 350 years old. Nevertheless, the Spanish nation of 40 million Spaniards has an extremely heterogeneous background, notwithstanding today's overwhelming Catholicism (of faith or at least culture). Thus today's Spanish people are actually Andalusians, Castilians, Catalans, Galicians, Basques and Roma(ni). The Basque people are also resident in southern France, while Romani people are spread all over Europe. Catalans form the majority of the people living in the separate polity of Andorra, while Galicians are also present within the Portuguese nation. That leaves Castilians and Andalusians only as peoples living solely within the boundaries of modern Spain. Thus, while the Spanish nation might seem to present a single one, it is actually an agglomeration of many different peoples, united within a single piece of territory (Biger, 1995, p. 476-477). By this token, it more that complies with the 'boundary-made nation' situation, as opposed to the one whereby 'the nation creates the boundary'.

\section{Asia: Syria, Lebanon, Israel and the Palestinian Authority}

The Asian part of the Mediterranean region is the Middle East. Aside from Egypt, this is a region lying in the south-western part of the Asian continent. As the cradle of civilisation this area is historically 'Old World', even though its nation-boundary relations fit more with the aforementioned 'New-World' model. Through to about a century ago, the whole area was in essence inhabited by the single nation of the Arabs (if with some minorities), even if the regime controlling it was that of Turkey's Ottoman Empire. Indeed, the main exceptions here were the Turks, as a nation migrating out of central Asia and becoming Moslems; as well as the Persians - also a non-Arab Moslem nation of unique status. It was European mandated regimes, mainly of Britain and France, that dictated the lines separating the Middle Eastern Arab nation into different territories that would later go on to become independent states (Biger, 2008). The mandating powers never looked at the dispersion of inhabitants of the area, fostering what would later become newly-independent states with no unique older history in any of them.

It was by this process, above all taking place in the 1920s, that the states of Iraq, Lebanon, Syria, Jordan (then Transjordan) and Palestine (Biger, 2004) were created, rather 'out of the Blue'. The process led to the creation of Syrian, Lebanese, Jordanian and Iraqi nations that had never existed before and were created in line with boundaries imposed on the Middle East by Europeans. Most of these independent states have been trying to develop their unique nationhood, but tribal, religious and other attitudes would seem to have prevented this so far (Blake \& Drysdale, 1985). The same held true for the Palestinians. A true Palestinian is a person, or the descendent of a person, who lived in the area which Britain created in 1920 and called Palestine, a name that had not 
existed within the formal division of the Ottoman Empire (Biger, 1981). Those who lived in British Palestine between 1920 and 1947 - and their offspring - are Palestinians, and there was no unique nation here before the British engaged in their creative act. Later, boundaries on the Arabian Peninsula were established on the basis of areas ruled by the leaders of local tribes, rather than in line with any nation-related characters (Al-Baharna, 1975).

The case of Israel is unique in the whole world as this polity was established along the lines of the 'nation state' model, as a Jewish state, which meant that it was not just for Jews that lived in the area, but for all the Jewish nation present as a diaspora in a great many different parts of the world. In general, the discussion surrounding the circumstances of Israel's creation and status is simply too complicated to be brought within the confines of the present paper, which has only generalising ambitions.

\section{Africa: Egypt, Libya, Tunisia, Algeria and Morocco}

For a century the area of North Africa was mainly inhabited by two nations mingled together. The majority were of the Arab nation, while the other key nation was that of the Berbers. Both were divided up into different tribes. Through to the First World War, the whole area was ruled by the European countries of Britain (in the case of Egypt), Italy (Libya) and France (Tunisia, Algeria, and Morocco). The modern boundaries of the different colonies and dependencies were created by the European rulers, without any intentions regarding the local people. When independent states emerged in this region, the boundaries laid down created Egypt, Libya, Tunisia, Algeria and Morocco, with the basic principle being that all who lived within the boundaries of those states affiliated themselves with the relevant nations concerned (Brownlie, 1979).

\section{Conclusions}

Although the model presented above cannot say much about the future, it highlights the ways in which today's independent states were established. On the one hand, the European Union is trying to avoid the nation-state idea (leaving aside 'Brexit'); while on the other, nations continue to achieve their independence (East Timor in 2002, Montenegro in 2006, and South Sudan and Kosovo in 2011). Some nations (like Catalonia and Chechnya) are still trying to achieve independence. In the face of these conflicting trends, there is no way of predicting what the future political map of the world will look like. However, the use of the models presented here does offer a clear insight into the manner of establishment of the global political map, and especially the map of the Mediterranean region.

The notion of the nation-state is well-known as a basic model, but the case whereby 'boundaries created nations' is discussed less often. However, the presentation of such a two-way model as has been discussed here may help with the understanding of the world map and of a Mediterranean region that is uniquely present on three great continents. The dual model may also perhaps go further in enhancing our understanding of what is a fragmented world. 


\section{References}

Al-Baharna, H. M. (1975). The Arabian Gulf States: Their legal and political status and their international problems. Beirut: Librairie Du Liban.

Biger, G. (1981). Where Was Palestine, Pre-World War I Perception. Area, 13(2), 153-160.

Biger, G. (1995). The Encyclopedia of International Boundaries. New York, NY: Facts on File.

Biger, G. (2004). The boundaries of Modern Palestine. London: Routledge Curzon.

Biger, G. (2008). Britain role as a boundary maker in the Middle East. In Z., Levey \& E., Podeh (Eds.). Britain and the Middle East: From Imperial Power to Junior Partner (pp. 21-32). Brighton: Sussex Academic Press.

Biger, G. (2011). On Nations and International Boundaries - The European Case. European Spatial Research and Policy, 18(2), 70-77. https://doi.org/10.2478/v10105-011-0013-0

Blake, G. H., \& Drysdale, A. (1985). The Middle East and North Africa: A Political Geography. Oxford, Oxford University Press.

Brownlie, I. (1979). African Boundaries: a Legal and Diplomatic Encyclopaedia. London, Los Angeles, CA: C. Hurst.

Ehrlich, E., Flexner, S. B., Carruth, G., \& Hawkins, J. M. (1980). Oxford American Dictionary. Oxford: Oxford University Press.

Girot, P. O. (Ed.). (1994). The Americas, World Boundaries (vol. 4). London: Routledge.

Gonen, A. (Ed.). (1993). The Encyclopaedia of the Peoples of the World. New York, NY: Henry Holt.

Ireland, G. (1971). Boundaries, Possessions and Conflicts in South America. New York, NY: Octagon Books.

King, R., Proudfoot, L., \& Smith, B. (Eds.). (1997). The Mediterranean - Environment and Society. London: Arnold.

Lanyi, G. A., \& McWilliams, W. C. (1966). Crisis and Continuity in World Politic. New York, NY: Random.

Minogue, K.R. (1967). Nationalism. London: B. T. Batsford.

Muir, R. (1975). Modern Political Geography. London: Macmillan Press.

Prescott, J. R. V. (1975). Map of Mainland Asia by Treaty. Melbourne: Melbourne University Press.

Touval, S. (1972). The Boundary Politics of Independent Africa. Cambridge, MA: Harvard University Press. WF (2018). The World Factbook. Washington, DC: CIA. 